\title{
Potensi Permintaan Angkutan Umum pada Rencana Rute Feeder di Kecamatan Kuta Alam, Kota Banda Aceh
}

\author{
Public Transport Demand Potential on Feeder Route Plan in \\ Kecamatan Kuta Alam, Banda Aceh City
}

\author{
Rio Erlangga ${ }^{1, \mathrm{a})}$, Cut Mutiawati $^{1, \mathrm{~b})}$, Fitrika Mita Suryani ${ }^{1, \mathrm{cc}}$ \& Marwan $^{1, \mathrm{~d})}$ \\ 1)Jurusan Teknik Sipil, Universitas Syiah Kuala, Banda Aceh 23111. \\ Koresponden : ${ }^{b}$ cutmutiawati@unsyiah.ac.id.
}

\begin{abstract}
ABSTRAK
Kemacetan sering terjadi di kota-kota di Indonesia terutama pada jam puncak pagi dan sore hari. Hal ini disebabkan oleh kurang berfungsinya angkutan umum. Masyarakat lebih memilih menggunakan angkutan pribadi untuk beraktivitas. Salah satu penyebabnya adalah karena kurangnya rute feeder yang dapat menjangkau wilayah permukiman. Oleh karena itu penelitian ini bertujuan untuk mengetahui potensi demand penumpang pada rencana rute feeder di lima kampung pada Kecamatan Kuta Alam Banda Aceh. Data yang telah dikumpulkan dianalisis dengan menggunakan Pedoman Teknis Penyelenggaraan Angkutan Umum di Wilayah Perkotaan Dalam Trayek Tetap dan Teratur, Departemen Perhubungan Tahun 2002. Hasil analisis diperoleh bahwa penduduk yang mau menggunakan angkutan umum lebih besar jumlahnya daripada jumlah penduduk yang tidak mau menggunakan angkutan umum yaitu 63\%. Jumlah angkutan umum feeder tertinggi didapatkan pada jam 07.00-07.59 WIB dan 08.00-08.59 WIB. Jenis moda yang dibutuhkan adalah MPU sebanyak 20 unit dan bus kecil sebanyak 12 unit. MPU layak secara finansial untuk rute rencana feeder karena jumlah yang dibutuhkan melebihi jumlah minimum yaitu 20 unit. Hal ini juga sesuai dengan lebar jalan pada rencana rute feeder.
\end{abstract}

Kata Kunci : manajemen fasilitas, rute feeder, penumpang potensial, angkutan umum.

\section{PENDAHULUAN}

Angkutan kota saat ini masih merupakan sarana transportasi yang paling banyak digunakan dan berperan dalam menunjang laju pembangunan, karena dapat menjangkau hampir seluruh wilayah pada suatu kawasan. Angkutan kota ini merupakan salah satu fasilitas kota yang vital bagi kehidupan kota. Oleh karena itu fasilitas tersebut harus bisa dikelola dengan baik selama masa hidupnya agar bisa selalu berfungsi dengan baik, secara ekonomis, efisien, dan efektif serta sesuai dengan prinsip green. Manajemen Aset Fasilitas siklus terdiri dari tahapan-tahapan sebagai berikut : perencanaan fasilitas, pengadaan fasilitas, sertifikasi dan inventarisasi fasilitas, pemakaian fasilitas, pengembangan fasilitas dan penghapusan fasilitas. Manajemen Aset Fasilitas mengenal dua tatarn manajemen : manajemen fasilitas dan manajemen organisasi pengelola fasilitas (Soemitro \& Suprayitno 2018)

Kota Banda Aceh merupakan salah satu kota di Aceh yang sedang giat melakukan pembangunan. Salah satunya dibidang moda transportasi umum yaitu Bus Transkoetaradja. Bus Trans Koetaradja beroperasi untuk mempermudah masyarakat dalam menggunakan angkutan umum sekaligus menekan angka penggunaan angkutan pribadi. Namun pada kenyataannya pelayanan Bus Transkoetaradja belum beroperasi secara optimal. Hal ini dikarenakan tidak ada 
rute feeder yang memadai sehingga menyulitkan masyarakat untuk dapat menuju rute utama yaitu rute Transkoetaradja

Sehubungan dengan hal itu maka diperlukan perencanaan rute angkutan feeder, salah satunya di Kecamatan Kuta Alam. Hal ini dilakukan agar mempermudah akses masyarakat yang tidak memiliki kendaraan pribadi maupun masyarakat yang mau beralih ke angkutan umum, baik untuk keperluan bekerja, berbisnis, sekolah, berbelanja, bersilaturahmi, maupun bepergian keluar kota. Tujuan penelitian ini untuk mendapatkan potensi penumpang angkutan feeder dan jumlah moda yang dibutuhkan pada rencana rute feeder di Kecamatan Kuta Alam.

Salah satu komponen perencanaan sistem operasional layanan bis kota adalah penentuan ukuran armada bus yang akan dioperasikan pada suatu koridor (Suprayitno \& Upa, 2016; Suprayitno \& Upa, 2017; Upa, 2017). Dua teknik pemodelan permintaan transportasi sudah pernah dipikirkan dan dicoba adalah model langsung dan model konvensional khusus (Suprayitno \& Upa, 2016; Suprayitno \& Upa, 2017; Upa, 2017; Soimun, 2018; Tamin, 2008).

Hasil penelitian ini dapat memberikan gambaran terukur tentang potensi permintaan angkutan feeder dan jumlah angkutan feeder yang dibutuhkan. Hasilnya diharapkan dapat menjadi salah satu bahan acuan bagi Pemerintah Kota Banda Aceh dalam membuat kebijakan pengoperasian angkutan umum di Kota Banda Aceh sehingga diharapkan penggunaan angkutan umum dapat meningkat untuk masa yang akan datang.

\section{STUDI PUSTAKA}

\section{Angkutan Umum}

Menurut Tamin (2000), angkutan dapat didefinisikan sebagai sarana yang digunakan untuk memindahkan orang atau barang dari lokasi ke lokasi yang lain. Angkutan bertujuan membantu orang atau kelompok orang menjangkau berbagai tempat yang dikehendaki atau mengirim barang dari tempat asalnya ke tempat tujuannya. Prosesnya dapat dilakukan menggunakan sarana angkutan berupa kendaraan atau tanpa kendaraan (diangkut oleh orang).

\section{Rute}

Menurut Departemen Perhubungan (2002), rute angkutan umum didefinisikan sebagai tempat-tempat pelayanan penumpang oleh angkutan umum yang dilakukan secara tetap, yaitu dengan menaikkan dan menurunkannya. Rute umumnya merupakan lintasan dari angkutan umum yang bersifat tetap dan melewati beberapa daerah, dimana angkutan umum dan penumpang melakukan interaksi secara rutin. Angkutan umum memberi pelayanan kepada penumpang dan penumpang juga menggunakan angkutan pada rute tersebut.

\section{Prediksi Jumlah Penduduk}

Menurut BPS (2018), penduduk dapat diartikan sebagai semua orang yang berdomisili di wilayah geografis Indonesia dalam kurun waktu selama enam bulan atau lebih, atau mereka yang bertujuan menetap walaupun masa domisili masih kurang dari enam bulan. Data populasi berdasarkan registrasi penduduk yang diperoleh dari catatan administrasi pada tingkat desa. Pada tingkat regional dan nasional data diperoleh dengan menambahkan satu catatan kedalam catatan lain untuk semua penduduk desa. Untuk mengetahui atau memprediksi jumlah penduduk pada tahun yang akan datang atau tahun yang direncanakan dapat dihitung dengan rumus proyeksi jumlah penduduk atau rumus geometrik. Rumus geometrik tersebut adalah :

$$
P_{n}=P_{0}(1+r)^{n}
$$

Keterangan : $P_{n}=$ Jumlah penduduk setelah $\mathrm{n}$ tahun ke depan (orang).

$P_{0}=$ Jumlah penduduk pada tahun awal (orang). 
$\mathrm{r} \quad=$ Angka pertumbuhan penduduk (jiwa).

$\mathrm{n} \quad$ = Jangka waktu dalam tahun (tahun).

\section{Sampel}

Menurut Sugiyono (2010), sampel adalah bagian dari jumlah dan merupakan karakteristik yang dimiliki oleh populasi. Populasi adalah wilayah generalisasi yang terdiri atas subjek atau objek yang mempunyai kualitas dan karakteristik tertenu yang ditetapkan oleh peneliti untuk dipelajari dan ditarik kesimpulan. Apabila dalam proses penelitian terhadap populasi yang besar, peneliti dibatasi oleh keterbatasan dana, tenaga dan waktu, tetapi peneliti ingin melakukan penelitian terhadap populasi tersebut maka peneliti menggunakan teknik pengambilan sampel, peneliti melakukan generalisasi kepada populasi yang diteliti. Pada proses ini sampel yang diambil dapat mewakili populasi tersebut (representatif).

Penetapan ukuran sampel dari populasi dapat juga menggunakan rumus Slovin, dimana penetapan sampel mempertimbangkan batas ketelitian yang dapat mempengaruhi kesalahan pengambilan sampel populasi. Rumus Slovin tersebut adalah sebagai berikut:

$$
n=\frac{N}{1+N e^{2}}
$$

$$
\begin{array}{rll}
\text { Keterangan : } & \mathrm{n}=\text { Jumlah sampel (orang) } \\
\mathrm{N} & =\text { Jumlah populasi (orang) } \\
\mathrm{e} & =\text { Nilai kritis/batas ketelitian yang diinginkan (e maksimum=10\%) }
\end{array}
$$

\section{Analisa Demand}

Menurut Tamin (2000), analisa demand digunakan untuk memprediksi jumlah kenaikan penumpang angkutan umum untuk kurun waktu lima tahun ke depan serta menjadi pertimbangan dalam proses penyediaan sarana dan prasarananya. Analisa ini dilakukan untuk memprediksi kenaikan atau penurunan jumlah calon penumpang angkutan umum untuk lima tahun kedepan, dari hasil analisa akan diketahui apakah akan terjadi kenaikan jumlah calon penumpang karena meningkatnya minat atau penurunan jumlah calon penumpang angkutan akibat berkurangnya minat calon penumpang karena beralih ke moda yang lain. Penyebab kenaikan jumlah penumpang dan bagaimana penyediaan sarana dan prasarananya atau penyebab terjadi penurunan jumlah (minat) calon penumpang diharapkan diketahui melalui analisa ini.

Departemen Perhubungan (2002), menyatakan bahwa perhitungan jumlah permintaan pelayanan angkutan umum penumpang meliputi tahap-tahap sebagai berikut :

1. Penentuan angka kepemilikan kendaraan pribadi

Persamaan angka kepemilikan kendaraan pribadi, sebagai berikut:

$$
K=\frac{V}{P}
$$

Keterangan : $\mathrm{K}=$ Angka pemilikan kendaraan pribadi (unit/orang);

$\mathrm{V}=$ Jumlah kendaraan pribadi (unit);

$\mathrm{P}=$ Jumlah penduduk seluruhnya (orang).

2. Penentuan kemampuan pelayanan kendaraan pribadi

Persamaan angka kemampuan pelayanan kendaraan pribadi (L), sebagai berikut :

$$
\mathrm{L}=P_{m} \times \mathrm{V} \times \mathrm{K}
$$

Keterangan $: \mathrm{L} \quad=$ angka kemampuan pelayanan kendaraan pribadi (unit)

$P_{m}=$ jumlah penduduk potensial (orang)

$\mathrm{V} \quad=$ jumlah kendaraan pribadi (unit) 


$$
\mathrm{K} \text { = angka kepemilikan kendaraan pribadi (unit/orang). }
$$

3. Penentuan jumlah penduduk potensial melakukan pergerakan

Persamaan jumlah penduduk potensial melakukan pergerakan dan membutuhkan pelayanan angkutan umum $(\mathrm{M})$, sebagai berikut:

$$
\mathrm{M}=\mathrm{Pm}-(\mathrm{Ll}+\mathrm{L} 2)
$$

Keterangan : $\mathrm{M}=$ Jumlah penduduk potensial(orang)

$\mathrm{Pm}=$ Jumlah penduduk potensial yang melakukan perjalanan(orang)

L1 = Kemampuan pelayanan kendaraan pribadi jenis mobil(org/unit)

L2 = Kemampuan pelayanan kendaraan pribadi jenis sepeda motor (org/unit)

$\mathrm{P}=$ Jumlah penduduk seluruhnya (orang).

4. Penentuan jumlah permintaan penumpang angkutan umum

Persamaan jumlah permintaan penumpang angkutan umum, sebagai berikut :

$D=\operatorname{ftr} x M$

Keterangan: $\mathrm{D}=$ Jumlah permintaan angkutan umum penumpang(orang)

$\mathrm{Ft}=$ Faktor kali jumlah penduduk potensial

$\mathrm{M}=$ Jumlah penduduk potensial (orang).

5. Penentuan jumlah kendaraan yang dibutuhkan

Persamaan jumlah kebutuhan kendaraan per hari, sebagai berikut:

$$
N=\frac{D}{P \min }
$$

Keterangan: $\mathrm{N}=$ Jumlah kebutuhan kendaraan (unit)

$\mathrm{D}=$ Jumlah permintaan angkutan umum penumpang (unit)

Pmin = Jumlah penduduk minimal per kendaraan per hari (orang).

\section{METODE PENELITIAN}

\section{Lokasi Penelitian}

Lokasi rencana rute angkutan umum feeder melewati beberapa desa pada Kecamatan Kuta Alam, yaitu Kampung Keuramat, Kampung Lambaro Skep, Kampung Bandar Baru, Kampung Mulia dan Kampung Lamdingin. Lima desa ini merupakan desa yang belum terlayani angkutan umum. Peta Rencana Rute feeder dapat dilihat pada Gambar 1 berikut. 


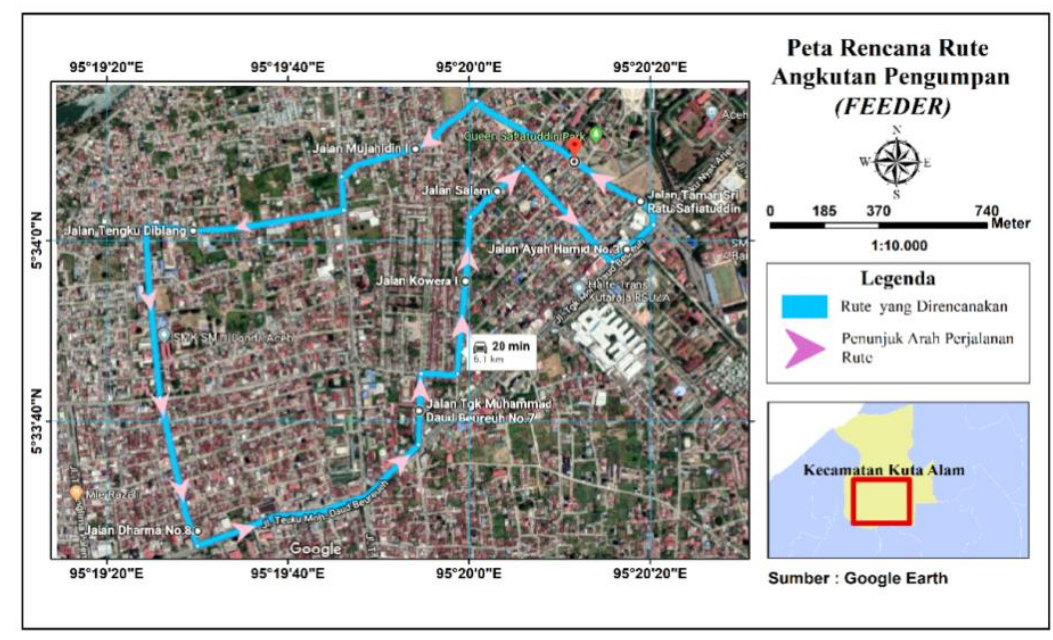

Gambar 1. Rute Feeder Rencana

\section{Metode Pengumpulan Data}

Tahapan analisis demand penumpang, penentuan moda, dan jumlah armada angkutan umum feeder membutuhkan data primer dan data sekunder yang diperoleh dari lapangan maupun dari dinas atau instansi terkait. Data yang diperlukan dalam penelitian ini adalah:

1. Data primer

Data primer yang dibutuhkan adalah jumlah penduduk yang mau menggunakan angkutan feeder. Data ini diperoleh dengan cara melakukan Home Interview Survey.

2. Data sekunder

Data sekunder yang dibutuhkan adalah jumlah penduduk pada lokasi penelitian, jumlah penduduk berdasarkan kelompok umur yang diperoleh dari Badan Pusat Statistik Provinsi Aceh, dan jumlah kepemilikan kendaraan pribadi.

Data jumlah penduduk yang mau menggunakan angkutan feeder diperoleh dengan Home Interview Survey pada rencana rute yang ditetapkan. Pengumpulan kuisioner dilakukan dengan mengunjungi rumah-rumah yang ada di lima kampung pada Kecamatan Kuta Alam yaitu Kampung Keuramat, Kampung Lambaro Skep, Kampung Bandar Baru, Kampung Mulia dan Kampung Lamdingin. Jumlah sampel minimal dihitung menggunakan rumus Slovin berdasarkan jumlah populasi (jumlah penduduk) masing-masing desa. Hasil perhitungan jumlah sampel dapat dilihat pada Tabel 1.

Tabel 1. Perhitungan Jumlah Sampel

\begin{tabular}{ccccc}
\hline No. & Kampung & $\begin{array}{c}\text { Populasi } \\
\text { (orang) }\end{array}$ & $\begin{array}{c}\text { Jumlah Sampel } \\
\text { minimal } \\
\text { (orang) }\end{array}$ & $\begin{array}{c}\text { Jumlah sampel } \\
\text { yang diperoleh } \\
\text { (orang) }\end{array}$ \\
\hline 1 & Keuramat & 4.686 & 35 & 46 \\
2 & Lambaro Skep & 5.398 & 41 & 51 \\
3 & Bandar Baru & 6.946 & 52 & 53 \\
4 & Mulia & 5.518 & 42 & 44 \\
5 & Lamdingin & 3.451 & 26 & 29 \\
\hline & & Total Sampel & $\mathbf{2 2 3}$ \\
\hline
\end{tabular}

\section{Pengolahan Data}


Analisis potensi permintaan berpedoman pada pedoman teknis penyelenggaraan Angkutan Umum di Wilayah Perkotaan Dalam Trayek Tetap dan Teratur (Departemen Perhubungan, 2002). Tahapan pengolahan data adalah sebagai berikut:

1. Penentuan kepemilikan kendaraan pribadi,

2. Penentuan kemampuan pelayanan kendaraan pribadi,

3. Penentuan jumlah penduduk potensial,

4. Penentuan permintaan jumlah penumpang,

5. Penentuan jumlah armada yang dibutuhkan

\section{HASIL DAN PEMBAHASAN}

\section{Karakteristik Responden}

Karakteristik responden terdiri dari umur, jenis kelamin, pendidikan dan pekerjaan. Umur responden dominan 24-50 tahun, dengan jenis kelamin laki-laki sebesar 52\%. Pendidikan terakhir responden dominan SMA dengan pekerjaan sebagai mahasiswa. Rincian masingmasing karakteristik responden dapat dilihat pada Gambar 2.

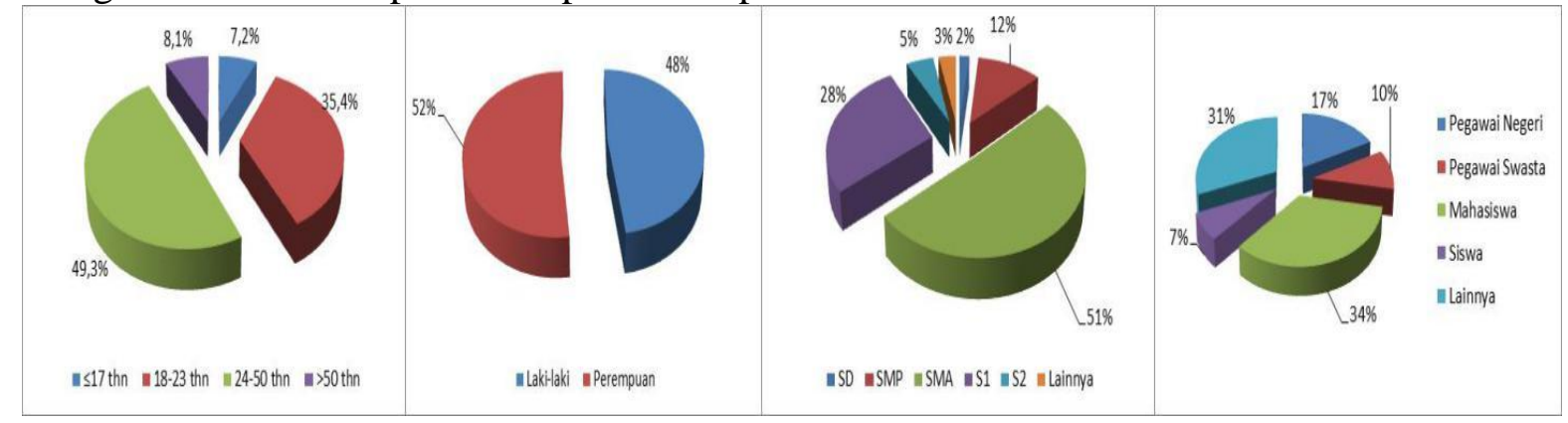

Gambar 2. Karakteristik Responden

\section{Tingkat Pertumbuhan Penduduk}

Tingkat pertumbuhan penduduk pada lokasi rute rencana feeder dihitung berdasarkan data penduduk tahun 2013 s/d 2018. Hasilnya menunjukkan bahwa tidak ada perbedaan yang signifikan pada masing-masing kampung. Rincian hasilnya dapat dilihat pada Tabel 2.

Tabel 2. Tingkat Pertumbuhan Rata-Rata Penduduk

\begin{tabular}{cclc}
\hline No. & Tahun & Kampung & $\begin{array}{c}\text { Tingkat Pertumbuhan } \\
\text { Rata-rata per-tahun } \\
(\%)\end{array}$ \\
\hline 1. & 2014 & Keuramat & 1,24 \\
2. & 2015 & Lambaro Skep & 1,23 \\
3. & 2016 & Bandar Baru & 1,24 \\
4. & 2017 & Mulia & 1,24 \\
5. & 2018 & Lamdingin & 1,23 \\
\hline
\end{tabular}

Berdasarkan nilai tingkat pertumbuhan, selanjutnya dihitung prediksi jumlah penduduk pada tahun rencana dihitung menggunakan rumus proyeksi. Hasilnya dapat dilihat pada Tabel 3.

Tabel 3. Jumlah Penduduk pada Tahun Rencana

\begin{tabular}{ccccccc}
\hline \multirow{2}{*}{ No. } & \multirow{2}{*}{ Kampung } & \multicolumn{5}{c}{ Jumlah Penduduk (orang) } \\
\cline { 3 - 6 } & & $\mathbf{2 0 1 9}$ & $\mathbf{2 0 2 0}$ & $\mathbf{2 0 2 1}$ & $\mathbf{2 0 2 2}$ & $\mathbf{2 0 2 3}$ \\
\hline 1 & Keuramat & 4.744 & 4.803 & 4.862 & 4.923 & 4.984 \\
\hline
\end{tabular}




\begin{tabular}{cllllll}
\hline \multirow{2}{*}{ No. Kampung } & \multicolumn{5}{c}{ Jumlah Penduduk (orang) } \\
\cline { 3 - 6 } & & $\mathbf{2 0 1 9}$ & $\mathbf{2 0 2 0}$ & $\mathbf{2 0 2 1}$ & $\mathbf{2 0 2 2}$ & $\mathbf{2 0 2 3}$ \\
\hline 2 & Lambaro Skep & 5.465 & 5.532 & 5.600 & 5.669 & 5.739 \\
\hline 3 & Bandar Baru & 7.032 & 7.119 & 7.208 & 7.297 & 7.387 \\
\hline 4 & Mulia & 5.586 & 5.655 & 5.725 & 5.796 & 5.868 \\
\hline 5 & Lamdingin & 3.494 & 3.537 & 3.580 & 3.624 & 3.669 \\
\hline
\end{tabular}

\section{Jumlah Penduduk Potensi Menggunakan Angkutan Umum Feeder}

Jumlah penduduk potensi menggunakan angkutan umum feeder didasarkan pada jumlah penduduk dengan kelompok umur 15-64 tahun. Kelompok umum ini berbeda dengan kriteria dari Departemen Perhubungan tahun 2002 yaitu penduduk dengan umur 5 tahun sampai dengan umur 65 tahun. Perbedaan ini karena peneliti berasumsi bahwa penduduk dengan umum 5-14 tahun tidak potensial menggunakan angkutan umum di Kota Banda Aceh saat ini. Berdasarkan data maka diperoleh jumlah penduduk potensi menggunakan angkutan umum feeder seperti pada Tabel 4.

Tabel 4. Jumlah Penduduk per-kelompok Umum di Kecamatan Kuta Alam

\begin{tabular}{ccccccc}
\hline \multirow{2}{*}{ Kelompok Umur Jumlah Penduduk (orang) } \\
\cline { 2 - 7 } & $\mathbf{2 0 1 3}$ & $\mathbf{2 0 1 4}$ & $\mathbf{2 0 1 5}$ & $\mathbf{2 0 1 6}$ & $\mathbf{2 0 1 7}$ & $\mathbf{2 0 1 8}$ \\
\hline $15-19$ & 5.056 & 4.578 & 4.772 & 4.794 & 4.838 & 4.904 \\
$20-24$ & 8.298 & 7.702 & 8.031 & 8.019 & 8.019 & 8.020 \\
$25-29$ & 6.257 & 5.883 & 6.189 & 6.288 & 6.377 & 6.437 \\
$30-34$ & 4.229 & 4.092 & 4.293 & 4.394 & 4.495 & 4.601 \\
$35-39$ & 3.608 & 3.408 & 3.630 & 3.722 & 3.838 & 3.958 \\
$40-44$ & 2.940 & 2.898 & 3.076 & 3.169 & 3.256 & 3.348 \\
$45-49$ & 2.358 & 2.295 & 2.466 & 2.564 & 2.669 & 2.775 \\
$50-54$ & 1.705 & 1.680 & 1.816 & 1.881 & 1.956 & 2.040 \\
$55-59$ & 1.249 & 1.318 & 1.432 & 1.506 & 1.578 & 1647 \\
$60-64$ & 913 & 927 & 1.022 & 1.084 & 1.155 & 1.230 \\
Total & 37.269 & 35.397 & 37.398 & 38.1221 & 38.918 & 39.741 \\
\hline
\end{tabular}

Sumber: Badan Pusat Statistik, 2018

\section{Kepemilikan Kendaraan Pribadi}

Tingkat pertumbuhan angkutan pribadi (mobil dan sepeda motor) dibutuhkan untuk memperkirakan jumlah kendaraan pribadi pada tahun rencana. Hasil tingkat pertumbuhan dan jumlah angkutan pribadi dapat dilihat pada Tabel 5.

Tabel 5. Tingkat Pertumbuhan Kendaraan Pribadi

\begin{tabular}{cccc}
\hline \multirow{2}{*}{ No. } & \multirow{2}{*}{ Kampung } & \multicolumn{2}{c}{ Tingkat Pertumbuhan rata-rata per-tahun (\%) } \\
\cline { 3 - 4 } & Keuramat & 1,0 & Sepeda Motor \\
\hline 1 & Lambaro Skep & 2,4 & 6,4 \\
2 & Bandar Baru & 2,9 & 10,8 \\
3 & Mulia & 2,2 & 7,1 \\
4 & Lamdingin & 0,6 & 8,7 \\
5 & & & 10,7 \\
\hline
\end{tabular}


Tingkat pertumbuhan sepeda motor lebih tinggi daripada mobil. Selanjutnya nilai tingkat pertumbuhan ini digunakan untuk memprediksi jumlah kendaraan pribadi pada tahun rencana dihitung menggunakan rumus proyeksi. Hasilnya dapat dilihat pada Tabel 6 dan Tabel 7.

Tabel 6. Jumlah Mobil pada Tahun Rencana

\begin{tabular}{ccccccc}
\hline \multirow{2}{*}{ No. } & \multirow{2}{*}{ Kampung } & \multicolumn{5}{c}{ Jumlah Mobil (Kendaraan) } \\
\cline { 3 - 7 } & & $\mathbf{2 0 1 9}$ & $\mathbf{2 0 2 0}$ & $\mathbf{2 0 2 1}$ & $\mathbf{2 0 2 2}$ & $\mathbf{2 0 2 3}$ \\
\hline 1 & Keuramat & 131 & 133 & 134 & 136 & 137 \\
\hline 2 & Lambaro Skep & 75 & 77 & 78 & 80 & 82 \\
\hline 3 & Bandar Baru & 254 & 261 & 269 & 276 & 284 \\
\hline 4 & Mulia & 113 & 116 & 118 & 121 & 124 \\
\hline 5 & Lamdingin & 56 & 57 & 57 & 57 & 58 \\
\hline
\end{tabular}

Tabel 7. Jumlah Sepeda Motor pada Tahun Rencana

\begin{tabular}{ccccccc}
\hline \multirow{2}{*}{ No. } & \multirow{2}{*}{ Kampung } & \multicolumn{5}{c}{ Jumlah Sepeda Motor (Kendaraan) } \\
\cline { 3 - 7 } & & $\mathbf{2 0 1 9}$ & $\mathbf{2 0 2 0}$ & $\mathbf{2 0 2 1}$ & $\mathbf{2 0 2 2}$ & $\mathbf{2 0 2 3}$ \\
\hline 1 & Keuramat & 1.554 & 1.653 & 1.758 & 1.870 & 1.989 \\
\hline 2 & Lambaro Skep & 1.668 & 1.848 & 2.048 & 2.269 & 2.515 \\
\hline 3 & Bandar Baru & 2.301 & 2.464 & 2.640 & 2.827 & 3.028 \\
\hline 4 & Mulia & 1.693 & 1.840 & 2.000 & 2.174 & 2.364 \\
\hline 5 & Lamdingin & 1.104 & 1.222 & 1.352 & 1.497 & 1.657 \\
\hline
\end{tabular}

\section{Analisa Potensi Permintaan (Demand)}

Analisis potensi permintaan (Demand) penumpang angkutan feeder dilakukan dengan tahapan sebagai berikut:

1. Angka kepemilikan kendaraan pribadi

Kepemilikan kendaraan pribadi pada Tabel 6 dan Tabel 7 menyatakan sepeda motor sebagai sarana angkutan pribadi terbesar yang dimiliki penduduk di Kecamatan Kuta Alam. Perhitungan angka kepemilikan kendaraan pribadi dapat dilihat pada Tabel 8.

Tabel 8. Perhitungan Angka Kepemilikan 2018

\begin{tabular}{ccccccc}
\hline No. & Kampung & $\begin{array}{c}\text { P } \\
\text { (orang) }\end{array}$ & $\begin{array}{c}\text { V1 } \\
\text { (unit) }\end{array}$ & $\begin{array}{c}\text { V2 } \\
\text { (unit) }\end{array}$ & $\begin{array}{c}\text { K1 } \\
\text { unit/org) }\end{array}$ & $\begin{array}{c}\text { K2 } \\
\text { (unit/org) }\end{array}$ \\
\hline 1 & Keuramat & 4686 & 130 & 1461 & 0.028 & 0.312 \\
2 & Lambaro Skep & 5398 & 73 & 1505 & 0.014 & 0.279 \\
3 & Bandar Baru & 6946 & 247 & 2148 & 0.036 & 0.309 \\
4 & Mulia & 5518 & 111 & 1557 & 0.020 & 0.282 \\
5 & Lamdingin & 3451 & 56 & 997 & 0.016 & 0.289 \\
\hline & Total & $\mathbf{2 5 . 9 9 9}$ & $\mathbf{6 1 7}$ & $\mathbf{7 . 6 6 8}$ & $\mathbf{0 . 0 2 4}$ & $\mathbf{0 . 2 9 5}$ \\
\hline
\end{tabular}

Keterangan : $\mathrm{K} 1=$ Angka pemilikan mobil (unit/orang)

$\mathrm{K} 2$ = Angka pemilikan sepeda motor (unit/orang)

V1 = Jumlah kendaraan mobil (unit) 


\begin{tabular}{ccccccc}
\hline No. & Kampung & $\begin{array}{c}\text { P } \\
\text { (orang) }\end{array}$ & $\begin{array}{c}\text { V1 } \\
\text { (unit) }\end{array}$ & $\begin{array}{c}\text { V2 } \\
\text { (unit) }\end{array}$ & $\begin{array}{c}\text { K1 } \\
\text { unit/org) }\end{array}$ & $\begin{array}{c}\text { K2 } \\
\text { (unit/org) }\end{array}$ \\
\hline V2 $=$ Jumlah kendaraan sepeda motor (unit) \\
$\mathrm{P}=$ Jumlah penduduk seluruhnya (orang) \\
\hline
\end{tabular}

2. Jumlah penduduk potensial melakukan pergerakan Jumlah penduduk potensial melakukan pergerakan dan membutuhkan pelayanan angkutan umum (M) dapat dilihat pada Tabel 9.

Tabel 9. Jumlah Penduduk Potensial Melakukan Perjalanan 2018

\begin{tabular}{cccccc}
\hline No. & Jam & $\begin{array}{c}\text { Pm } \\
\text { (orang) }\end{array}$ & $\begin{array}{c}\text { L1 } \\
\text { (orang) }\end{array}$ & $\begin{array}{c}\text { L2 } \\
\text { (orang) }\end{array}$ & $\begin{array}{c}\text { M } \\
\text { (orang) }\end{array}$ \\
\hline 1 & $07: 00-07: 59$ & 2657 & 270 & 2239 & 148 \\
\hline 2 & $08: 00-08: 59$ & 2718 & 276 & 2290 & 151 \\
\hline 3 & $09: 00-09: 59$ & 1087 & 111 & 916 & 60 \\
\hline 4 & $10: 00-10: 59$ & 1208 & 123 & 1018 & 67 \\
\hline 5 & $11: 00-11: 59$ & 60 & 6 & 51 & 3 \\
\hline 6 & $12: 00-12: 59$ & 0 & 0 & 0 & 0 \\
\hline 7 & $13: 00-13: 59$ & 0 & 0 & 0 & 0
\end{tabular}

Tabel 9. Jumlah Penduduk Potensial Melakukan Perjalanan 2018 (Lanjutan)

\begin{tabular}{cccccc}
\hline No. & Jam & $\begin{array}{c}\text { Pm } \\
\text { (orang) }\end{array}$ & $\begin{array}{c}\text { L1 } \\
\text { (orang) }\end{array}$ & $\begin{array}{c}\text { L2 } \\
\text { (orang) }\end{array}$ & $\begin{array}{c}\text { M } \\
\text { (orang) }\end{array}$ \\
\hline 8 & $14: 00-14: 59$ & 302 & 31 & 254 & 17 \\
\hline 9 & $15: 00-15: 59$ & 60 & 6 & 51 & 3 \\
\hline 10 & $16: 00-16: 59$ & 362 & 37 & 305 & 20 \\
\hline 11 & $17: 00-17: 59$ & 60 & 6 & 51 & 3 \\
\hline 12 & $18: 00-18: 59$ & 0 & 0 & 0 & 0 \\
\hline
\end{tabular}

Keterangan :

$\mathrm{Pm}=$ Jumlah penduduk potensial yang melakukan perjalanan(orang)

L1 = Kemampuan pelayanan kendaraan pribadi jenis mobil(org/unit)

L2 = Kemampuan pelayanan kendaraan pribadi jenis sepeda motor (org/unit)

$\mathrm{M}$ = Jumlah penduduk seluruhnya (orang)

3. Jumlah permintaan penumpang angkutan umum feeder

Jumlah permintaan penumpang angkutan umum (D) dapat dilihat pada Tabel 10.

Tabel 10. Jumlah Permintaan Penumpang Angkutan Umum 2018

\begin{tabular}{ccccc}
\hline No. & Jam & Ftr & $\begin{array}{c}\text { M } \\
\text { (orang) }\end{array}$ & $\begin{array}{c}\text { D } \\
\text { (orang) }\end{array}$ \\
\hline 1 & $07: 00-07: 59$ & 2 & 148 & 296 \\
\hline 2 & $08: 00-08: 59$ & 2 & 151 & 302 \\
\hline 3 & $09: 00-09: 59$ & 2 & 60 & 121 \\
\hline 4 & $10: 00-10: 59$ & 2 & 67 & 134 \\
\hline 5 & $11: 00-11: 59$ & 2 & 3 & 7 \\
\hline 6 & $12: 00-12: 59$ & 2 & 0 & 0 \\
\hline
\end{tabular}




\begin{tabular}{rcccc}
\hline No. & Jam & Ftr & $\begin{array}{c}\text { M } \\
\text { (orang) }\end{array}$ & $\begin{array}{c}\text { D } \\
\text { (orang) }\end{array}$ \\
\hline 7 & $13: 00-13: 59$ & 2 & 0 & 0 \\
\hline 8 & $14: 00-14: 59$ & 2 & 17 & 34 \\
\hline 9 & $15: 00-15: 59$ & 2 & 3 & 7 \\
\hline 10 & $16: 00-16: 59$ & 2 & 20 & 40 \\
\hline 11 & $17: 00-17: 59$ & 2 & 3 & 7 \\
\hline 12 & $18: 00-18: 59$ & 2 & 0 & 0 \\
\hline
\end{tabular}

Keterangan:

Ftr $=$ Faktor kali jumlah penduduk potensial

$\mathrm{M}=$ Jumlah penduduk potensial (orang)

$\mathrm{D}$ = Jumlah permintaan angkutan umum penumpang(orang)

4. Jumlah armada yang dibutuhkan

Jumlah angkutan umum feeder yang dibutuhkan setiap kampung dapat dilihat pada Tabel 11.

Tabel 11. Jumlah Feeder yang Dibutuhkan Tahun Rencana

\begin{tabular}{|c|c|c|c|}
\hline \multirow{2}{*}{ Jam } & \multirow{2}{*}{$\begin{array}{l}\text { \% Kemauan Pengguna } \\
\text { Angkutan Feeder }\end{array}$} & \multicolumn{2}{|c|}{ Jumlah Angkutan yang Dibutuhkan } \\
\hline & & MPU & Bus Kecil \\
\hline 07:00 -07:59 & 19.731 & 20 & 12 \\
\hline 08:00 -08:59 & 20.179 & 20 & 13 \\
\hline 09:00 -09:59 & 8.072 & 8 & 5 \\
\hline $10: 00-10: 59$ & 8.969 & 9 & 6 \\
\hline $11: 00-11: 59$ & 0.448 & 0 & 0 \\
\hline $12: 00-12: 59$ & 0.000 & 0 & 0 \\
\hline $13: 00-13: 59$ & 0.000 & 0 & 0 \\
\hline $14: 00-14: 59$ & 2.242 & 2 & 1 \\
\hline $15: 00-15: 59$ & 0.448 & 0 & 0 \\
\hline $16: 00-16: 59$ & 2.691 & 3 & 2 \\
\hline $17: 00-17: 59$ & 0.448 & 0 & 0 \\
\hline $18: 00-18: 59$ & 0.000 & 0 & 0 \\
\hline
\end{tabular}

Standar Departemen Perhubungan 2002 mensyaratkan jumlah minimum angkutan per hari (R) untuk jenis Mobil Penumpang Umum (MPU) dan Bus Kecil adalah 20 unit perhari. Hal ini dimaksudkan agar operasional angkutan umum layak dan menguntungkan secara finansial. Hasil penelitian ini menunjukkan untuk angkutan feeder jenis MPU memenuhi syarat yaitu 20 unit, namun untuk jenis bus kecil tidak tercapai 20 unit perhari. Berdasarkan hasil tersebut maka rute feeder dengan jenis moda MPU layak untuk dibuka. Moda jenis MPU sesuai dengan lebar jalan pada rencana rute feeder tersebut.

\section{KESIMPULAN DAN SARAN}


Berdasarkan pada hasil penelitian yang telah dilakukan dapat diambil beberapa kesimpulan sebagai berikut :

- Penduduk yang mau menggunakan angkutan umum feeder jumlahnya lebih besar daripada jumlah penduduk yang tidak mau menggunakan angkutan umum feeder, yaitu diangka $63 \%$.

- Jumlah angkutan umum feeder tertinggi didapatkan pada jam 07.00-07.59 WIB dan 08.00-08.59 WIB dengan angkutan jenis MPU sebanyak 20 unit dan angkutan jenis bus kecil sebanyak 12 unit.

- Moda dengan jenis MPU layak secara finansial untuk rute rencana feeder karena jumlah yang dibutuhkan melebihi jumlah minimum yaitu 201 unit. Hal ini juga sesuai dengan lebar jalan pada rencana rute feeder.

Saran yang bisa diberikan adalah perlu adanya penelitian lanjutan tentang perencanaan rute feeder dan potensi kebutuhan untuk kawasan Banda Aceh secara menyeluruh agar rute utama yang ada dapat diakses dengan mudah oleh masyarakat. Selanjutnya dapat dilakukan analisis ekonomi dan analisis finansial terhadap pengoperasian angkutan umum feeder di Kecamatan Kuta Alam Kota Banda Aceh.

\section{DAFTAR PUSTAKA}

BPS Provinsi Aceh. (2018). Kecamatan Kuta Alam dalam Angka 2018. Banda BPS Aceh.

Departemen Perhubungan. 2002. Pedoman Teknis Penyelenggaraan Angkutan Penumpang Umum di Wilayah Perkotaan dalam Trayek Tetap dan Teratur. Direktorat Jenderal Perhubungan Darat. Departemen Perhubungan.

Soemitro, R.A.A \& Suprayitno, H. (2018). "Pemikiran Awal tentang Konsep Dasar Manajemen Aset Fasilitas". Jurnal Manajemen Aset Infrastruktur \& Fasilitas, Vol.2, No.1, Juni 2018.

Soimun, A. (2018). Analisis Probabilitas Perpindahan Moda Pengguna Kendaraan Pribadi (Sepeda Motor dan Mobil) ke Kereta Api Commuter Surabaya Sidoarjo. Tesis Magister. Departemen Teknik Sipil. Institut Teknologi Sepuluh Nopember (ITS). Surabaya.

Sugiyono, (2010). Metode Penelitian Administrasi: Pendekatan Kuantitatif, Kualitatif dan $R \& D$. Penerbit Alfabeta. Bandung. Indonesia.

Suprayitno, H. \& Upa, V. A. (2016). "Mamminasata BRT User Trip Characteristics for the Design of Demand Modelling Method for a New BRT Line". IPTEK. The Journal for Technology and Science, Vol. 27, Issue. 3, 47-52.

Suprayitno, H. \& Upa, V. A. (2017), "Special Conventional Transport Model for a New BRT Line Passenger Demand Prediction”. JTSS - Journal of Technology and Social Science, Vol. 1, Issue 3, 10-18.

Suprayitno, H. \& Ryansyah, M. (2018). "Karakteristik Pelaku dan Perilaku Perjalanan Penumpang Bus Trans Koetaradja”. Jurnal Aplikasi Teknik Sipil. Volume 16, Nomor 2, $55-62$.

Tamin, Ofyar Z. (2000). Perencanaan dan Permodelan Transportasi. Penerbit ITB, Bandung, Indonesia.

Upa, V. A. (2017). Perhitungan Jumlah Permintaan Potensial Bus Rapid Transit (BRT) Mamminasata Koridor 1 dengan menggunakan Special Conventional Transport Model. Tesis Magister. Jurusan Teknik Sipil. Institut Teknologi Sepuluh Nopember (ITS). Surabaya. 


\section{(e)ISSN 2615-1847 (p)ISSN 2615-1839}

Jurnal Manajemen Aset Infrastruktur \& Fasilitas - Vol. 4, No. 4, Oktober 2020 